\title{
Preface by the General Editors
}

In the thirty years after Robert Louis Stevenson's death in 1894, no fewer than eight collected editions of his works were published. Even in an age when such projects were more common (and economically feasible) than they are now, that is an unusually high number, and it testifies to the endurance of Stevenson's popularity over the first portion of the twentieth century. For the publishers involved, these were commercial rather than scholarly ventures, understandably so. Little effort was made to establish the accuracy of individual works. In most cases the editions reprinted texts that drew, either directly or at several removes, on the twenty-eight-volume Works of Robert Louis Stevenson [Edinburgh Edition] (1894-98) overseen by Stevenson's literary executor, Sidney Colvin. With good intentions and what now looks like questionable judgment, Colvin actively re-edited all of the works, altered some, and suppressed others. He also had neither the means nor any compelling motivation to try to untangle the often complicated transmission history of many of the texts in his care. As a result, though the Works of Robert Louis Stevenson [Edinburgh Edition] gathered and made widely accessible nearly all of Stevenson's numerous literary productions, it preserved them in forms that deviate in countless ways from what Stevenson actually wrote.

The New Edinburgh Edition of the Works of Robert Louis Stevenson pays titular tribute to Colvin's foundational assemblage. It aims, though, to provide what cannot be found in his or any subsequent collected edition, namely accurate texts for all of Stevenson's substantial oeuvre. The New Edinburgh Edition is designed to appeal both to the general reader and the scholar. Each volume supplies attractive, uncluttered reading texts. Individual works are thoroughly annotated, allowing readers to grasp the full range of Stevenson's allusions as well as to recover the myriad ways in which he responded to the contemporary world and his cultural heritage. Introductory essays trace composition and publication histories while providing contextual information designed to extend readers' understanding and, we hope, enhance their appreciation. Textual essays describe the extant witness texts (e.g. manuscript, proof-sheet, periodical publication, single or multiple book editions) for each work as well as the relations among 
them, while laying out the rationales for the copy texts chosen for the New Edinburgh Edition. In each volume, the textual apparatus provides a full listing of emendations and substantive variants. Overall, we trust that these volumes will help throw into higher relief Stevenson's distinctive achievements as a creative writer.

Those achievements extend across virtually all literary genres. During his lifetime Stevenson was known as a writer of exceptional versatility and skill. His output — in a career of only twenty years—included not just short and long prose fiction, but travel writing, essays, journalism, biography, poetry, drama, and-near the end of his life - ethnographic and political studies of the South Seas. Much of this writing has fallen from view, and for some time now Stevenson's reputation has rested, sturdily enough, on a small number of works: Treasure Island, Strange Case of Dr Jekyll and Mr Hyde, Kidnapped, a few essays, a handful of poems and short stories. By bringing back into print works once highly regarded but long unavailable, the New Edinburgh Edition provides a more complete picture not only of Stevenson's career but of his place in modern literary history. While it would of course be disingenuous to claim the same high aesthetic merit for each of his works, few are of mere historical interest. In this edition, readers will also find collected in one place pieces, most notably essays and short stories, that for various reasons were either never published or never reprinted after their initial periodical publication. Five volumes of Essays and four of Short Stories for the first time gather together in a uniform critical edition Stevenson's substantial output in these genres.

Henry James called Stevenson 'a Scotchman of the world', meaning that while his imagination remained rooted in his homeland- it is a good fortune for a genius to have had such a country as Scotland for its primary stuff', James notes - he was also a thoroughly cosmopolitan writer who drew inspiration from many literary and cultural traditions outside his own. In his life, too, Stevenson travelled through large portions of the habitable globe without ever losing sight, as it were, of his birthplace. As befits so peripatetic a writer, the volume editors for the New Edinburgh Edition are themselves drawn from across Europe, North America, and the South Pacific. In a sense, nothing less than a global effort would suffice for an undertaking such as this one. For one thing, Stevenson's manuscripts and other materials are scattered in archives, libraries, and personal collections around the world. For Colvin and his immediate successors, the inaccessibility of much of this material would have frustrated any aspirations - had they had anyto produce an authoritative collected works. Since the 1970s, a num- 
ber of excellent editions of individual works have been published (and are acknowledged in the appropriate volumes here), but the far-flung dispersal of the relevant sources has until now discouraged efforts to produce a coordinated series of texts covering Stevenson's entire oeuvre, all prepared by careful study of manuscripts and variant readings in lifetime editions and following unified scholarly procedures.

Stevenson's travels are relevant to the New Edinburgh Edition in another way. All evidence indicates that Stevenson, when he had the chance, preferred to be-indeed, insisted on being-minutely involved in the production of his works. An inveterate reviser and meticulous proofreader, at every stage from manuscript to final publication, Stevenson not only made changes but cancelled those made by, for instance, copy editors or typesetters. Unlike the vast majority of nineteenth-century authors, who happily ceded to printers the task of tidying up their manuscripts to conform to a particular house style, Stevenson resisted efforts to regularize the punctuation or even the grammar of his texts. One of his American editors, Edward Bok, wrote that 'no man ever went over his proofs more carefully than did Stevenson'. This level of oversight, however, was seldom possible even in the best of circumstances. After 1887, as the Stevenson household moved from upstate New York to California to various locations in the South Pacific, it became virtually impossible. The sheer distances involved compelled Stevenson to relinquish much of his control once a work left his desk. Colvin's editorial hand was heaviest, but errors and 'corrections' could creep in at multiple points in the line of transmission. Add to this the fact that Stevenson contracted with many different publishers in Great Britain and the United States, that his works often were issued more or less simultaneously in both countries under different imprints, that many of his shorter pieces appeared in periodicals before being revised and collected in volumes, that his more popular works went through multiple editions in short spaces of time, and that pirated editions abound, and the task of producing authoritative texts can be seen in all its fascinating, daunting complexity.

With these considerations in mind, we have sought to devise editorial principles marked by rigour and consistency, but also flexibility. No single policy for copy text can be adopted because of the varying conditions of production that obtained at different moments in Stevenson's career. Editors will normally take as copy text the most authoritative early edition - that is, the edition corresponding to the period in which Stevenson worked with greatest concentration and most sustained effort on the piece in question. In most but far from all cases, 
this means the first book edition of a work. For short texts (stories, essays, poems), the first publication in volume form is preferred to periodical publication as the version most carefully prepared and overseen by the author. In all cases, our aim is to publish accurate versions of texts as mediated by the differing circumstances of production and publication in which Stevenson collaborated. The New Edinburgh Edition of the Collected Works of Robert Louis Stevenson thus makes available, often for the first time, authoritative texts that scholars and critics can use in their work and that all readers can rely on. 